\title{
Forum
}

\section{Bringing Classics to the State Schools of the Midlands: A Year in the Life of the WCN}

\author{
Paul Grigsby
}

Key words: Widening Participation, Outreach, Roman Coventry, Diversity

\section{Introduction}

The Warwick Classics Network (WCN) was created in July 2018 with funding from the Warwick Widening Participation Development Fund and the Warwick Impact Fund. Further funding from Widening Participation (WP) and the charity Classics for All secured the continuation of the position of Research Fellow in Outreach and Impact for the Dept. of Classics and Ancient History, a role given to Dr Paul Grigsby; WP funding was also used to cover the expenses of events such as our $2^{\text {nd }}$ July 2018 WCN Launch event and the 2019 Warwick Ancient Drama Festival. For the period April 2019-April 2020 the WCN received further funding from WP, Classics for All, and the A. G. Leventis Foundation, and this report will detail the activities that this funding supported.

Our WCN website can be accessed here. www.warwick.ac.uk/wcn

\section{Introducing Classics to local Schools}

With the help of Classics for All, Classics was introduced to several local Coventry schools in September 2019, these being Barr's Hill School, President Kennedy School, Stoke Park School, Cardinal Wiseman School, and West Coventry Academy, as well as Lawrence Sheriff School in Rugby.

At Barr's Hill School, Classics was introduced to every Year 7 student regardless of ability (130 students). The first unit focused on Pompeii and Latin following the Cambridge Latin Course (CLC) textbook. The second unit focused on Ovid's Metamorphoses. 46 Year 7 pupils from Barr's Hill also attended the 'Coventry: A City of Cultures event' in July 2019 which funded students from local schools for a visit with talks and workshops to the Herbert Gallery in Coventry and Lunt Roman Fort. [WCN are developing this project further with their Roman Coventry Project (see below), a massive undertaking involving local Coventry Schools in 2020/2021]. In September 2019, every Barr's Hill student in Year 7 began studying Latin for 5 hours a week, working on a rotation system so every student enjoyed 6 weeks of Classics, 5 hours a week, aiming for 30

Author of correspondence: Paul Grigsby, Email: Paul.Grigsby@warwick.ac.uk

Cite this article: Grigsby P (2020). Bringing Classics to the State Schools of the Midlands: A Year in the Life of the WCN The Journal of Classics Teaching 21, 88-91. https://doi. org/10.1017/S2058631020000537 hours total for every student. In Year 7 they studied Latin in Stages 1-4 of the CLC Book 1 and a school-designed course based on Ovid's Metamorphoses in English translation. In addition, from September 2020 every Year 8 student will now be studying Classics for 7 weeks, with 4 hours in each week, in total 28 hours for every student.

President Kennedy School, Coventry introduced MegaGreek as part of an extra-curricular Classics club for 50 Year 7 students. Charlie Andrew, from the charity Classics for All, led a training day for staff. Charlotte Stentoft, a teacher from the school who delivered the lessons, reported on the training - 'Both of us started the day with zero previous knowledge or experience of ancient Greek, but left feeling empowered and confident to start teaching by the training.' They will be looking to use student leaders from Year 8 from September 2020 and later offering the club to Year 8 students as well. Paul Grigsby took VR headsets into the school for a Year 7 High Attainers' club and invited the students to our WCN project 'Coventry: A City of Cultures'.

With the help of WCN, Stoke Park School, Coventry received a grant from Classics for All to launch a Classics Project for Year 7s in September 2019. Pupils received three lessons a week and were taught Latin using the CLC as well as exploring the Rise and Fall of the Roman Empire. Around 180 Year 7 pupils were involved and this will expand this coming academic year with Latin being taught in both Years 7 and 8 .

West Coventry Academy has introduced a Classics club in 2020 providing extra-curricular Classics to around 20 pupils.

At Lawrence Sheriff School, Rugby, WCN and Steve Hunt of Classics for All created a ten-week course on Ancient Greece, which was led by their Head of Politics, Nick Wharton, in enrichment sessions.

As the chart (below) shows, prior to the formation of the WCN, just 8 of the 54 State Secondary schools in Warwickshire offered any dedicated curriculum time to Classics subjects. Due to the work of the WCN, from September 2019 this increased to 14 schools, from $15 \%$ to $25 \%$ of the whole. We are currently working with more schools, and our aim is to get Classics into $45 \%$ of Warwickshire state secondaries by September 2021.

Thanks to our funding, the WCN we can say that from September 2021 almost 1000 Coventry students will have benefitted directly from our work through gaining Classics at their schools, with hundreds more benefitting through attendance at our campus events. 


\section{State-maintained secondary schools in Warwickshire which offer / do not offer Classics}

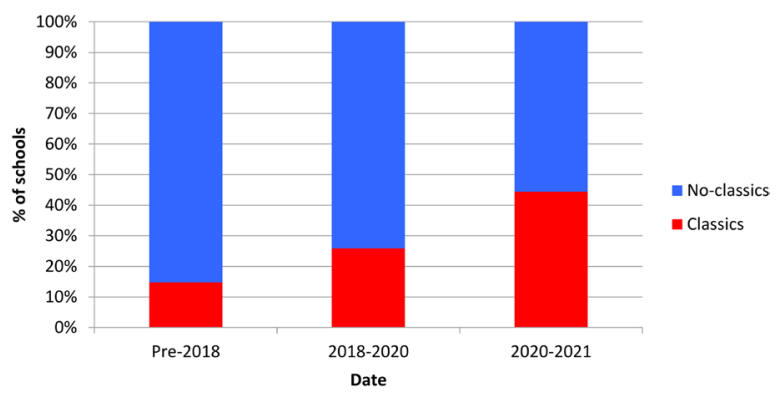

\section{Schools Going Forwards}

The WCN has approached over 60 Warwickshire state schools since April 2018 with a view to introducing Classics. A timeline of our school interactions including other news can be found here.

https://warwick.ac.uk/fac/arts/classics/research/outreach/warwickclassicsnetwork/latest/

In addition, with our Roman Coventry Project (see below), we already have over 30 local schools interested in taking part including 25 primary schools, with an aim to eventually involving all the schools in Coventry.

\section{WCN Events and Activities 2019-2020}

Thanks to the support given by our funders the WCN has developed into a very successful operation. Both Paul Grigsby and Prof. Michael Scott were nominated for the Warwick Public Engagement Contribution Award 2019. Below is a summary of the main events and activities undertaken by the WCN during the period covered by this round of current round of funding.

\section{\#AskAnAcademic Videos}

In November 2018 the WCN was awarded $£ 500$ from the Warwick Public Engagement Fund to develop its project \#AskAnAcademic. This is a video resource in which Warwick Classics academics answer questions sent in by schools relating to the Ancient History and Classical Civilisation GCSE and A level curricula. In addition, these videos allow our WCN academics to talk about their latest research and to promote their work to the wider public.

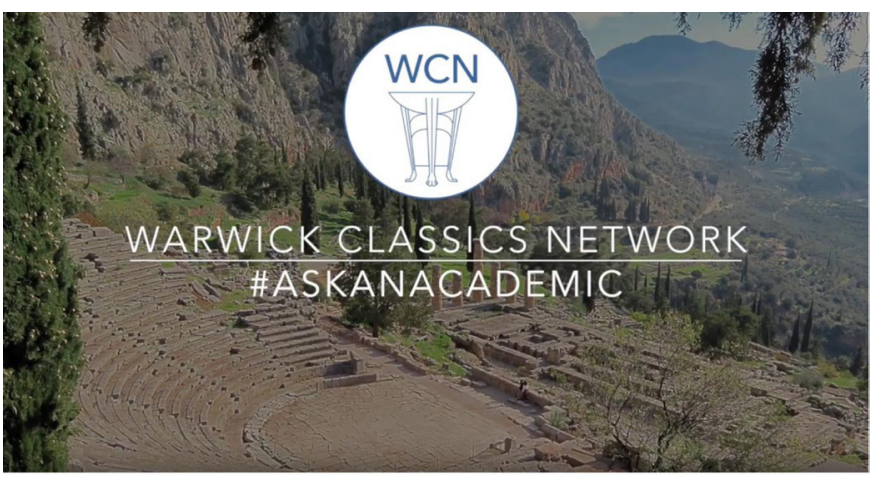

The first video, posted at the beginning of February 2019, featured Prof. James Davidson speaking on Love and Relationships. These videos are promoted online via social media and to our WCN contacts, including all WP schools across Warwickshire. Our aim with this project is to increase resources for those already teaching or learning Classics, but also to increase the availability of this subject to non-classicists, including those WP schools. Our other videos include: Prof. Zahra Newby on Myth, Art and Architecture; Prof. Michael Scott on the Ancient Greek Symposium; Dr Clare Rowan on Imperial Image and Coins; and Prof Michael Scott on Greek Religion. So far, the videos have had almost 6,000 views online. Read more here: https://warwick.ac.uk/fac/arts/classics/research/outreach/warwickclassicsnetwork/stoa/videosetc/askanacademic/

More videos will be created in 2020/2021.

\section{Coventry: A City of Cultures}

In January 2019 the WCN were awarded $£ 2,000$ for the project 'Coventry: A City of Cultures' from the Connecting Cultures Global Research Priority at the University of Warwick. This project involved collaboration between the Department of Classics and Ancient History here at Warwick and academics from the Coventry University, along with the Herbert Museum and Gallery in Coventry, Lunt Roman Fort site, and local Coventry schools. In this project, we investigated the role played by the meeting of cultures in the development of Coventry, and are creating a teaching resource online for future use in bringing local history and Classics to local schools.

As part of this project, Paul Grigsby organised a social networking meeting at the Oculus Building on campus between members of the Department of Classics, academics from Coventry University, museum staff from the Herbert Gallery in Coventry and from the Warwickshire Museum in Warwick. The meeting was a great success and connections were forged that will continue to build between Warwick and its local community. We are especially excited about the idea of collaborative exhibitions to be organised for our planned Antiquities Room, which we aim to use as a means of bringing Classics to the wider community, including local schools. In addition, Paul used this event to foster stronger links with some of our local schools, opening up the idea of university study as a viable option to more pupils.

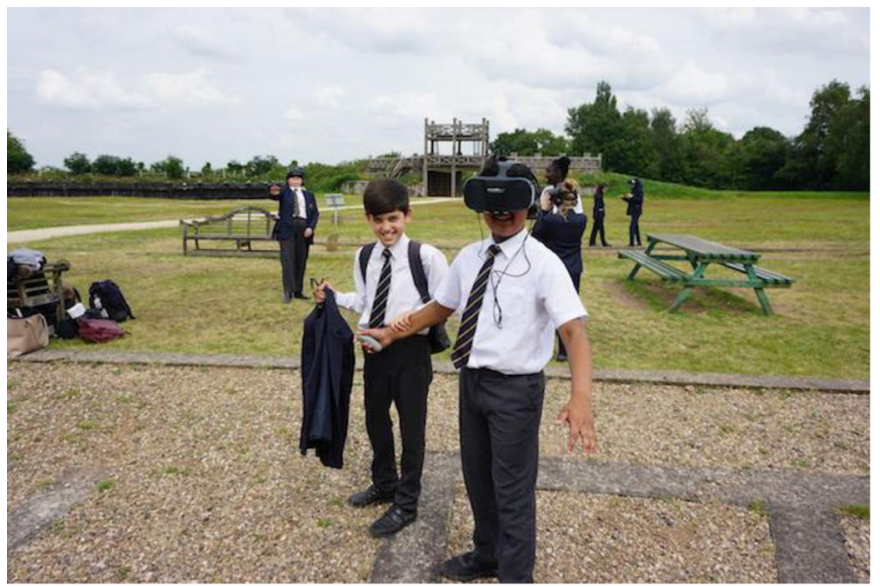

The project culminated with a visit to the Herbert Gallery and Lunt Roman Fort (above) on $8^{\text {th }}$ July 2019 for 46 pupils from Barr's Hill School and 16 from President Kennedy School. These schools also introduced Classics through the help of the WCN and Classics for All in September 2019. The day involved object handling, gallery tours and academic sessions at the Herbert, followed by a tour of Lunt Fort. More information can be found here.

https://warwick.ac.uk/fac/arts/classics/research/outreach/ warwickclassicsnetwork/events/cityofcultures/ 
We will be continuing this project as an ongoing programme, which will link local schools to Warwick University and to Lunt and the Herbert Gallery as a continuing process, offering more local schools the opportunity to join into this network and benefit from the presence of a nearby university (see Roman Coventry Project below for more details).

\section{Classical Civilisation A-level Teachers' Day - 1st July 2019}

On $1^{\text {st }}$ July 48 teachers from across the country attended the Department of Classics Classical Civilisation A-level Teachers' Day. Sessions led by our academics were recorded and have been posted online. These resources can be used to interest WP schools in Classics. A full report of the day and access to resources can be found here.

https://warwick.ac.uk/fac/arts/classics/research/outreach/warwickclassicsnetwork/events/classcivteachersday/

So far, the videos from this day have been viewed over 3,000 times.

In 2020 we organised a second Classical Civilisation Teachers' Day. Postponed due to Covid-19, this event was rescheduled as a very successful online event which took place on 11th November 2020. For more details see here: https://warwick.ac.uk/fac/arts/ classics/warwickclassicsnetwork/events/classciv2020/

\section{FIECCA 2019}

On $7^{\text {th }}$ July Paul Grigsby spoke at the joint Classical Association and FIEC conference at University College London about the work of the WCN as part of a panel organised by Prof. Edith Hall and Dr Arlene Holmes-Henderson of the charity Advocating Classics Education. Paul Grigsby spoke about the important role played by Warwick WP in funding this work and about our successes with local WP schools. A brief report can be found here.

http://aceclassics.org.uk/ace-panel-at-classical-association-fiec-conference/

\section{Sutton Trust Summer School July 29th - Aug $2^{\text {nd }} 2019$}

The WCN was involved in the organisation of the 2019 Sutton Trust Summer School here at Warwick. We created an exciting course for interested pupils working together with the departments of History of Art and Film and TV, examining how Classics has been a constant theme throughout art history, and how Classics is used in modern film and TV media. We discussed especially the themes of spectacle and the body, and Paul Grigsby led a session on Greek Religion.

The Sutton Trust targets WP schools in its efforts to open university as an option to pupils from areas of traditionally low university uptake. WCN has used its contacts and social media to advertise this classics summer school, and we have received a cohort of 19 students this year.

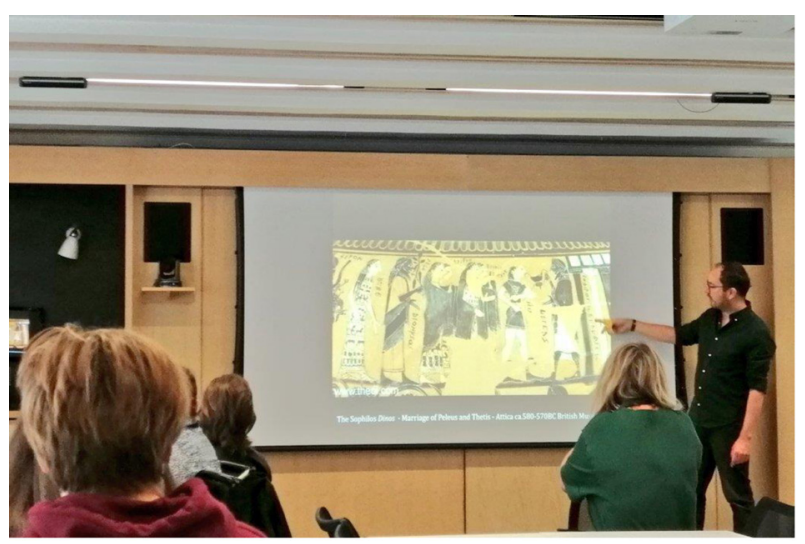

\section{Sutton Trust Summer School July $27^{\text {th }}$ - Jul $37^{\text {st }} 2020$}

Paul Grigsby once again co-ordinated and ran the Classics/History of Art/Film \& TV strand of this year's Sutton Trust Summer School 2020 , which this year was an online event. The videos which he created for the event will be adapted and made available online as part of our WCN resources for use in schools across the country.

\section{Warwick Classics 'Ancient Worlds Day’ 21st November 2019}

On Thursday 21st November the WCN and Dept. of Classics and Ancient History at Warwick held our 2019 Warwick Classics Network Study Day entitled 'Ancient Worlds'. We welcomed almost 1000 school children and members of the public to the campus to hear talks by authors Caroline Lawrence, Alexandra Sheppard, Emily Hauser and Natalie Haynes, as well as sessions led by our own Warwick Classics academics.

Caroline Lawrence, author of The Roman Mysteries series spoke on Myths, Movies and Storytelling; Alexandra Sheppard, author of Oh My Gods spoke on '21st Century Gods'; Emily Hauser author of the best-selling Golden Apple Trilogy gave a talk on 'Rewriting Ancient Greek Myths in Fiction'; and Natalie Haynes, author of The Amber Fury, The Children of Jocasta, and creator of BBC's Stand up for the Classics gave a talk entitled 'Troy Story', about all things Trojan and her latest best-seller A Thousand Ships.

In addition, our Warwick Classics Academics led sessions on their own interests and specialities in the Ancient World: Eric Csapo and Emmanuela Bakola on 'The stories about Achilles' birth and death: art, epic, myth and drama'; Alison Cooley on 'The Stones of Pompeii tell tales'; Victoria Rimell and David Fearn on 'Four Classical Poems: The Wow of Narrative'; and Michael Scott on 'Heracles - he does get around'.

Organised through the generous support of the A. G. Leventis Foundation, the day comprised of morning sessions for KS2-KS3 pupils and afternoon sessions for students in key stages 4 and 5 . Members of the public also attended along with Warwick students and staff.

We targeted WP schools in our promotion of this event and attendees included pupils from Barr's Hill, President Kennedy, Sidney Stringer and Stoke Park. More information on the day can be found here. https://warwick.ac.uk/fac/arts/classics/research/outreach/warwickclassicsnetwork/events/ancientworlds/

In addition, videos were made during the day for use in schools around the country unable to attend. So far, these videos have been viewed over 2,500 times.

https://warwick.ac.uk/fac/arts/classics/warwickclassicsnetwork/ events/ancientworlds/videos/

\section{Warwick Classics 'Ancient Worlds Day' 2021}

Our second Ancient Worlds Day, set for $11^{\text {th }}$ November, has been postponed to March 2021 because of the knock-on effect of Covid-19. We are again hoping for a successful day for 250 school children (social distancing is reducing numbers). More information can be found here:

https://warwick.ac.uk/fac/arts/classics/warwickclassicsnetwork/ events/ancientworlds 2021

\section{Overview of the actions of the WCN in figures}

Through our various WCN activities on and off campus since April 2019, we have reached well over 1,000 pupils and over 130 teachers from schools across the country. We have made contact with almost 100 new schools in addition to maintaining continual 
contact with all schools who have attended past events with emails highlighting events and resources. We currently have over 200 schools in our WCN contact list receiving regular updates about the hub's activities.

Of these students, about 400 were from WP schools, a substantial increase on previous years and achieved through specific targeting. Our main events such as the Drama Day and Ancient Worlds Day are still dominated by independent schools, but this reflects the current situation of classics teaching in the UK, something which the WCN with WP help has been aiming to change.

Above all we are keen to introduce familiarity with Warwick both through on- and off- campus events/activities, thus giving WP pupils a chance to consider university as an option open to them.

\section{Going Forwards}

\section{Outreach Group}

In October 2019 Paul Grigsby created an Outreach Group of Warwick Undergraduates interested in taking Classics into local schools, especially WP schools with no previous access to Classics. Students led sessions at Sidney Stringer Academy, Barr's Hill School, and President Kennedy School, introducing Classics in extra-curricular clubs and High-Attainers' Groups. This group will continue in 2020/2021 and Paul Grigsby will also be organising part of this year's Warwick Classics Portfolio in which projects will be set up with local WP schools based on the Roman Coventry project.

\section{Online Resources}

Our biggest success was the creation of online resources in tandem with Classics for All, primarily based on the Ancient History GCSE curriculum and overseen by WCN with the help of teachers from across the country. In addition, Classical Civilisation A-level resources are also being created. The WCN have also created and collated resources from across the country and other Classics for All networks for Key Stage 2, Key Stage 3, Home Schooling, BAME and Diversity, Latin and Greek, and Ancient History and Classical Civilisation. The aim of our Key Stage 2 and 3 resources is to give WP schools and other schools not traditionally teaching Classics the chance to get some Classics onto the curriculum. This link with Warwick will hopefully inspire these WP students to see study at university as a viable option.

The online resources can be viewed here:

https://warwick.ac.uk/fac/arts/classics/warwickclassicsnetwork/stoa/

Our WCN resources have received over 100,000 visits since the March lockdown.

\section{Roman Coventry Project 2020-2021}

The WCN is developing an ambitious project on Roman Coventry that will tie in with Coventry City of Culture 2021. Our aim is to use Coventry's heritage assets - such as the Herbert Art Gallery and Museum, Warwickshire Museum and the Lunt Roman Fort - to help bring a wider range of subjects to the schools of Coventry, providing enrichment and cultural capital centred on Coventry's unique ancient Roman past.

We will be working with each of these institutions and with Warwick Manufacturing Group to bring Coventry's ancient world to life for the school children of Coventry and wider Warwickshire. As well as creating this exciting project, we aim to help give the schools of Coventry the opportunity of further increasing their cultural capital through the introduction of Classics/Ancient History onto their curriculum. Our aim is to offer every single Coventry school access to lessons/resources on Roman Coventry alongside some Latin language to help bring Roman Coventry to life for a new generation. From a WP perspective, this exposure to the work of the university and chance to meet staff and students will hopefully reveal further education as a viable and attainable target. So far over 30 Coventry schools have signed up as part of this project.

In the early summer of 2021 (July) we will celebrate this project with a Festival of Roman Coventry. This is to be held either in Coventry or at the Warwick Arts Centre/Oculus on campus, and it will be a multi-layered event that will celebrate the work of all our participating schools, their teachers and students. Guest speakers will include Caroline Lawrence, Dr Simon Elliott, and Prof Michael Scott. As part of this festival there will be workshops led by Classics for All on introducing Classics to the curriculum, as well as sessions for Classics teachers which will be based around the Ancient History resources created by Classics for All.

The end point will be the creation of resources on Roman Coventry/Warwickshire which will be hosted on the WCN website and made available to all schools going forward.

Paul Grigsby is working with Marie Diebolt to target especially the WP schools for this project. Paul has already created a suite of Teacher Resources:

https://warwick.ac.uk/fac/arts/classics/warwickclassicsnetwork/romancoventry/resources/

$\mathrm{He}$ is also developing an online virtual museum using technology and expertise of the Warwick Manufacturing Group. For more information on this project, follow this link:

https://warwick.ac.uk/fac/arts/classics/warwickclassicsnetwork/ romancoventry/

\section{Final Words}

The WCN will continue as a priority to target WP schools and to create and disseminate resources to our local WP schools. The online resources we are creating will be made available to all schools via the WCN website and advertised accordingly, being especially used to target approaches to WP schools. In addition, our VR Headsets and associated resources and lesson plans will continue to be used in local WP schools.

Thanks to the help of Classics for All, the A. G. Leventis Foundation, and all our funders, the WCN has created a vast network of Classics teachers, with resources and events bringing the work of Warwick Classics and the excitement of university study to many pupils across the country. With our Roman Coventry project aiming to reach every school in Coventry over the coming year, we are pleased to be continuing this work into 2021 and beyond. 